\title{
Wheelchair users' perceived exertion during typical mobility activities
}

\author{
$\mathrm{L} \mathrm{Qi}^{1,2}, \mathrm{M}$ Ferguson-Pell ${ }^{2}, \mathrm{Z}$ Salimi ${ }^{2}, \mathrm{R} \mathrm{Haennel}^{2}$ and A Ramadi ${ }^{2}$
}

Study design: Each participant performed a series of wheelchair exercises equivalent in intensity to minimal functional speed $\left(1 \mathrm{~m} \mathrm{~s}^{-1}\right)$, functional walking speed $\left(1.3 \mathrm{~m} \mathrm{~s}^{-1}\right)$, a relatively challenging speed $\left(1.6 \mathrm{~m} \mathrm{~s}^{-1}\right)$ and a self-selected speed. Each participant also completed a graded exercise test (GXT) to volitional exhaustion $\left(\mathrm{VO}_{2 \text { peak }}\right)$.

Objectives: The purpose of this study was (1) to assess the physical capacity of wheelchair users as they undertake typical mobility activities and (2) to investigate how closely the components of a differentiated model of perceived exertion mirror wheelchair users' own perception of exertion.

Methods: Eleven (eight males and three females) spinal cord-injured or congenitally impaired wheelchair-dependent participants volunteered for the study. Differentiated ratings of perceived exertion ( $\mathrm{RPE}_{\text {_arm }}$ and $\left.\mathrm{RPE}_{\text {_respiration}}\right)$ and oxygen uptake $\left(\mathrm{VO}_{2}\right)$ and heart rate were recorded during each exercise.

Results: The mean comfortable speed at which the participants propelled their own wheelchairs on the wheelchair ergometer was $1.1 \pm 0.2 \mathrm{~m} \mathrm{~s}^{-1}$. Speeds of $1 \mathrm{~m} \mathrm{~s}^{-1}$ and $1.3 \mathrm{~m} \mathrm{~s}^{-1}$ are typical of everyday functional propulsion. The corresponding RPE_respiration and RPE_arm ranged from 7 to 13 on the Borg scale; the $\% \mathrm{VO}_{2 \text { peak }}$ measured in these trials ranged from 37 to $80 \% \mathrm{VO}_{2 \text { peak. }}$ For propulsion intensities used in the present study_low, moderate, high and graded exercise intensity — no difference could be observed between $\mathrm{RPE}_{\text {respiration }}$ and RPE_arm. There were no significant differences between RPE_arm and RPE_respiration at the termination of the GXT. Conclusion: The current study showed potential for the use of RPE to assess and monitor daily wheelchair propulsion intensity in individuals with paraplegia.

Spinal Cord (2015) 53, 687-691; doi:10.1038/sc.2015.30; published online 17 March 2015

\section{INTRODUCTION}

People who become wheelchair dependent for mobility because of a spinal cord injury (SCI) must face a double challenge: they have to overcome new obstacles in carrying out activities of daily living and adapt to new ways of maintaining their physical fitness. If they do not keep fit they may become less able to carry out their daily tasks and they may see their general health deteriorate and become subject to such risks as obesity, diabetes and cardiovascular disease. ${ }^{1-3}$

Although some activities of daily living provide in themselves opportunities for exercise, guided physical training may be included during the initial phase of rehabilitation to initiate a program of routine exercises. Such programs are recommended for maintaining fitness in the long term and a physically active lifestyle with the associated health benefits. ${ }^{4,5}$ It stands to reason that wheelchair users need and want to play a major part in designing and monitoring their individual program, and much of their input and choices will be based on their own perception of what constitutes a reasonable intensity of exercise. Objective measurements in a clinical setting may help assess the level of exercise intensity, but consistent adherence to an exercise program is likely based on the wheelchair user's own perception of exercise intensity.

Borg's rating of perceived exertion (RPE) scale has become an accepted tool in both the assessment and prescription of exercise. ${ }^{6}$
There have been a few studies in which wheelchair users' metabolic responses and RPE were recorded during wheelchair exercises and hand-cycling training, ${ }^{7-9}$ but they have generally used treadmill or hand cycling at relatively high intensities for elite wheelchair athletes. ${ }^{10,11}$ Daily activities at lower intensities have greater relevance for the majority of wheelchair users. One of the strategies for promoting regular physical activities is assisting people in making close estimates of daily physical activity levels that are conducive for maintaining satisfactory physical capacity.

The purpose of this study was therefore (1) to assess the physical capacity of wheelchair users as they undertake typical mobility activities; and (2) to relate the differentiated perceived effort to physical capacity. As the majority of wheelchair activities do not require maximal effort but rather a repetitive sustained sub-maximal effort, muscle fatigue may be a particularly relevant aspect of wheelchair propulsion. Where upper body exercise is concerned, wheelchair users' arms may fatigue sooner than their cardiorespiratory system. ${ }^{8}$ The Differentiated RPE model considers the two perceived signals separately: one peripheral, from the working muscles, the other metabolic, from the cardiorespiratory system. It is thus possible to determine when fatigue is greater in one or the other. Most of all, we are interested in finding a good correlation between wheelchair users' RPE and physical capacity so that they can use this simple scale to

${ }^{1}$ Department of Biomedical Engineering, Dalian University of Technology, Dalian, Liaoning, China and ${ }^{2}$ Faculty of Rehabilitation Medicine, University of Alberta, Edmonton, Alberta, Canada

Correspondence: Professor M Ferguson-Pell, University of Alberta, South Academic Building, Edmonton, Alberta, Canada T6G 2G7.

E-mail: martin.ferguson-pel|@ualberta.ca

Received 6 August 2014; revised 20 January 2015; accepted 22 January 2015; published online 17 March 2015 
Table 1 Characteristics of participants

\begin{tabular}{|c|c|c|c|c|c|c|}
\hline Participant code & Sex & Age (year) & Weight (kg) & Type of injury & ASIA impairment scale grade & Time since injury (year) \\
\hline 1 & M & 35 & 50.4 & $\mathrm{SCl}$ & T10 AISA A & 2 \\
\hline 2 & M & 45 & 68.3 & $\mathrm{SCl}$ & T12/L1 AISA A & 2.5 \\
\hline 3 & M & 41 & 97.2 & $\mathrm{SCl}$ & T6/T7 AISA A & 18 \\
\hline 4 & M & 34 & 68.4 & $\mathrm{SCl}$ & T12 AISA A & 17 \\
\hline 5 & M & 49 & 80.5 & $\mathrm{SCl}$ & T11 AISA A & 2 \\
\hline 6 & M & 33 & 93.1 & Spina bifida & $\mathrm{T} 10$ & 18 \\
\hline 7 & M & 47 & 99.2 & $\mathrm{SCl}$ & T6 AISA B & 12 \\
\hline 8 & M & 44 & 125.4 & $\mathrm{SCl}$ & T11 AIS A & 10 \\
\hline 9 & $\mathrm{~F}$ & 55 & 73.4 & $\mathrm{SCl}$ & T11 AISA A & 3.5 \\
\hline 10 & $\mathrm{~F}$ & 29 & 57.8 & Spina bifida & L2 & 12 \\
\hline 11 & $\mathrm{~F}$ & 51 & 64.1 & $\mathrm{SCl}$ & T12 AISA A & 18 \\
\hline Mean (s.d.) & & $42.1(8.4)$ & $79.8(22.0)$ & - & - & $10.4(6.9)$ \\
\hline
\end{tabular}

Abbreviations: ASIA, American Spinal Injury Association; F, female; M, male; SCI, spinal cord injury; s.d., standard deviation.

Table 2 Peak values observed at the termination of the GXT

\begin{tabular}{cccccccccc}
\hline Test & $V O_{\text {peak }}\left(\mathrm{m} / \mathrm{min}^{-1} \mathrm{~kg}^{-1}\right)$ & $H R_{\text {rest }}(B P M)$ & $H R_{\max }(B P M)$ & $V E_{\text {peak }}\left(\mathrm{l} \mathrm{min}{ }^{-1}\right)$ & $R E R_{\text {peak }}$ & Work load (W) & Time (s) & $R P E($ respiratory) & $R P E($ arm $)$ \\
\hline GXT & $16.3 \pm 4.2$ & $81 \pm 11$ & $151 \pm 14$ & $63 \pm 23$ & $1.5 \pm 0.3$ & $63.2 \pm 17.4$ & $620 \pm 172$ & $17.1 \pm 2.1$ & $17.5 \pm 2.2$
\end{tabular}

Abbreviations: BPM, beats per min; GXT, graded exercise test; HRmax, maximal heart rate; HRrest, heart rate at rest; RER, respiratory exchange ratio; RPE, rating of perceived exertion; VE, expired volume per unit time; $\mathrm{VO}_{2 \text { peak }}$, peak oxygen consumption per unit time.

NOTE: values are mean \pm s.d.

self-monitor their daily activity intensities in a way that would benefit their health. Beyond these results, we see an additional value of this study in its pilot nature, intended to show possible directions of future research with more, and less heterogeneous, participants.

\section{MATERIALS AND METHODS}

\section{Participants}

Eleven (eight males and three females) wheelchair-dependent participants with SCI at the T6 level or below volunteered for the study. Table 1 shows the injury and physical characteristics of each participant.

Oxygen uptake $\left(\mathrm{VO}_{2}, 1 \mathrm{~min}^{-1}\right)$, carbon dioxide output $\left(\mathrm{VCO}_{2}, 1 \mathrm{~min}^{-1}\right)$ and minute ventilation $\left(V_{\mathrm{E}}, 1 \mathrm{~min}^{-1}\right)$ were continuously measured using a computerized gas analyzing system (Oxycon Mobile, Jaeger, Bunnik, The Netherlands). Respiratory-gas exchange measurements were obtained every $5 \mathrm{~s}$. System calibration was undertaken before each trial. Heart rate (HR, beats per min) was monitored continuously by telemetry (Timex, TIMEX Group Canada, Inc., Markham, ON, Canada).

The participant's own wheelchair was secured to an instrumented roller ergometer, which was connected to a monitor placed in front of the participant to provide visual speed feedback. The ergometer consisted of two independent cylindrical steel rollers with radius $0.158 \mathrm{~m}$ and a mass of $26.4 \mathrm{~kg}$, one for each rear wheel, supported by pillow-block bearings (NSK P208, Tokyo, Japan) within a wooden structure to support the wheelchair. Work load was controlled through friction applied to each roller by a fabric strap attached to pneumatic actuators of a digital pressure controller (FESTO, Esslingen am Neckar, Germany), with a proportional valve to regulate the required air pressure. The desired work load through friction was controlled by a computer program (NI LabVIEW 2012, National Instruments Corporation, Austin, TX, USA)

\section{Test procedure and ratings of perceived exertion}

RPE were measured using the 15-point Borg scale. Before starting the exercise protocol, all participants received an orientation, including standardized instructions on how to report their feeling of exertion: ease/difficulty of breathing as RPE_respiration, perceived body temperature and the localized exertion in shoulders and arms as RPE arm.
Participants warmed up for about 5 min while getting used to the ergometer and visual propulsion speed feedback. They were then asked to perform a set of 3-min wheelchair propulsion bouts at different speeds. Data were recorded at a self-selected comfortable speed, $1 \mathrm{~m} \mathrm{~s}^{-1}$ (minimal safe speed to cross an intersection with traffic lights), $1.3 \mathrm{~m} \mathrm{~s}^{-1}$, which is equivalent to typical ablebodied walking speed, and $1.6 \mathrm{~m} \mathrm{~s}^{-1}$ (the upper limit of a self-selected speed among people with paraplegia). The order of exercise bouts was randomized. Perceptual ratings ( $\mathrm{RPE}_{\text {respiration }}$, and $\mathrm{RPE}$ arm $)$ were obtained at the end of each exercise bout. A 5-min passive rest period was given between bouts. The rest period also allowed the participants' HR to return approximately to baseline.

After a 15-min rest, participants performed a graded maximal exercise at a constant speed of $1 \mathrm{~m} \mathrm{~s}^{-1}$ to exhaustion. The work load was set at $10 \mathrm{~W}$ and then increased by $5 \mathrm{~W}$ every minute until exhaustion. Two of the participants were engaged in regular paraplegia sports. For them the work load was increased in steps of $10 \mathrm{~W}$ so that volitional exhaustion could occur within 8-14 min. The end point of the test was determined when the participant volitionally stopped because of fatigue or the investigators determined that the participant could not maintain the expected speed after three warnings. Participants were asked every $2 \mathrm{~min}$ to give two ratings (RPE_respiration and $\mathrm{RPE}_{\text {arm }}$ ) of perceived exertion by nodding to the applicable numbers on the Borg scale. The Borg scale was placed in full view of the participants throughout the exercise trials.

\section{Data analysis}

The mean values of the oxygen uptake were calculated over the final $30 \mathrm{~s}$ of each constant speed trial. For the graded exercise tests (GXTs), regression analysis was used to identify the time windows equivalent to 40,60 and $80 \%$ $\mathrm{VO}_{2 \text { peak }}$, and then RPE values, $\mathrm{HR}$ and work load were determined in reference to their respective time windows. Metabolic peak values observed at the termination of GXT were used to normalize the values measured during constant speed trials.

\section{Statistics}

Statistical analysis was performed using SPSS (SPSS for Windows Version 16.0; SPSS, Inc, Chicago, IL, USA). The normality of the test data was confirmed by the Shapiro-Wilk test $(P>0.05)$. The analysis of covariance (ANCOVA) was 
Table 3 RPE values, HR and work load during graded exercise test at 40,60 and $80 \% \mathrm{VO}_{2 \text { peak }}$

\begin{tabular}{|c|c|c|c|c|c|}
\hline$\% \mathrm{VO}_{2 p e a k}$ & $R P E_{\text {respiration }}$ & $R P E_{-a r m}$ & $H R$ (beats per min) & $\% H R_{\max }$ & Work load (W) \\
\hline 40 & $9.4 \pm 0.7$ & $9.2 \pm 0.9$ & $103.4 \pm 18.8$ & $0.66 \pm 0.01$ & $15.7 \pm 1.9$ \\
\hline 60 & $11.2 \pm 1.8$ & $10.9 \pm 1.8$ & $114.0 \pm 15.5$ & $0.77 \pm 0.06$ & $27.2 \pm 10.4$ \\
\hline
\end{tabular}

Abbreviations: $\% \mathrm{VO}_{2 \text { peak, }}$ percentage peak oxygen consumption per unit time; $\mathrm{HR}$, heart rate; RPE, rating of perceived exertion.

NOTE: values are mean + s.d.

Table 4 Descriptive statistics reported during constant speed wheelchair propulsion tests

\begin{tabular}{|c|c|c|c|c|}
\hline Variables & $\begin{array}{c}\text { Self-selected speed } \\
\left(1.1 \pm 0.2 \mathrm{~ms}^{-1}\right)\end{array}$ & $1 \mathrm{~ms}^{-1}$ & $1.3 \mathrm{~ms}^{-1}$ & $1.6 \mathrm{~ms}^{-1}$ \\
\hline$\% \mathrm{VO}_{2 \text { peak }}$ & $53.2 \pm 9.3^{a}$ & $53.8 \pm 10.3^{a}$ & $63.7 \pm 15.2$ & $71.6 \pm 11.6^{a}$ \\
\hline $\begin{array}{l}\text { HR(beats } \\
\text { per min) }\end{array}$ & $104 \pm 18$ & $103 \pm 16$ & $111 \pm 17$ & $121 \pm 20$ \\
\hline$\% \mathrm{HR}_{\max }$ & $0.69 \pm 0.09$ & $0.68 \pm 0.10$ & $0.73 \pm 0.10$ & $0.79 \pm 0.11$ \\
\hline VE $\left(I \min ^{-1}\right)$ & $23 \pm 6^{a}$ & $24 \pm 6^{a}$ & $28 \pm 6$ & $36 \pm 8^{a}$ \\
\hline RPE_respiration & $8.9 \pm 1.9^{a}$ & $9.8 \pm 2.2^{\mathrm{a}}$ & $10.3 \pm 1.7$ & $12.4 \pm 2.1^{a}$ \\
\hline RPE_arm & $9.3 \pm 2.5$ & $9.6 \pm 2.4$ & $10.3 \pm 2.6$ & $12.1 \pm 2.0$ \\
\hline
\end{tabular}

Abbreviations: $\% \mathrm{VO}_{2 \text { peak, }}$ percent of peak oxygen consumption per unit time; $\mathrm{HR}$, heart rate; $\%$ $H R_{\text {max }}$, percent of maximal heart rate; VE, expired volume per unit time; RPE, rating of perceived exertion.

asignificant difference between propulsion speeds $(P<0.05)$

NOTE: Values are mean \pm s.d.

used to compare two regression lines ( $\mathrm{RPE}_{\text {rrespiration }}$ and $\mathrm{RPE} \_$arm ) by controlling $\% \mathrm{VO}_{2 \text { peak }}$ and work load for the graded exercise test. One-way analysis of variance was used to compare $\% \mathrm{VO}_{2 \text { peak }}, \mathrm{HR}, V_{\mathrm{E}}, \mathrm{RPE}_{\text {_respiration }}$ and $\mathrm{RPE}_{\text {arm }}$ between different wheelchair propulsion speeds. The paired t-test was used to compare the difference between RPE_respiration and RPE arm values recorded at different speeds and GXT. All data are reported in the text as mean \pm s.d. Significance was set at $P<0.05$ for all statistical procedures.

Statement of ethics. We certify that all applicable institutional and governmental regulations concerning the ethical use of human volunteers were followed during the course of this research.

\section{RESULTS}

Graded exercise tests

Peak values observed at the termination of GXT are reported in Table 2. Analysis of covariance showed that there were no significant differences between RPE_respiration and RPE_arm when regressed against $\% \mathrm{VO}_{2 \text { peak }}$ and work load. Table 3 shows RPE responses, power output, $\mathrm{HR}$ and $\% \mathrm{HR}_{\max }$ at different $\% \mathrm{VO}_{2}$ peak levels. The paired $t$-test showed no significant difference between RPE_respiration and $\mathrm{RPE}_{\text {arm }}$ at different $\% \mathrm{VO}_{2}$ peak levels during the GXT tests.

\section{Constant speed tests}

Descriptive statistics of the constant speed wheelchair propulsion tests are reported in Table 4 . The mean comfortable speed held by the participants was $1.1 \pm 0.2 \mathrm{~m} \mathrm{~s}^{-1}$. Speeds of 1 and $1.3 \mathrm{~m} \mathrm{~s}^{-1}$ are daily functional propulsion speeds. The RPE reported by the participants ranged from 7 to 13 ; the mean $\% \mathrm{VO}_{2 \text { peak }}$ corresponding to these trials

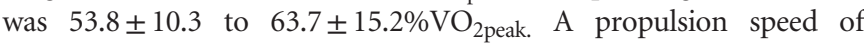
$1.6 \mathrm{~m} \mathrm{~s}^{-1}$ represents a relatively more strenuous intensity; the RPE reported for mean $\mathrm{RPE}_{\text {respiration }}$ and $\mathrm{RPE}$ _arm was $12.4 \pm 2.1$, and $12.1 \pm 2.0$, respectively. The $\mathrm{HR}$ and $\% \mathrm{VO}_{2 \text { peak }}$ during $1.6 \mathrm{~m} \mathrm{~s}^{-1}$ propelling were $121 \pm 20$ beats per $\min \left(\begin{array}{llll}0.79 \% & \left.\mathrm{HR}_{\max }\right) & \text { and }\end{array}\right.$ $71.6 \pm 11.6 \% \mathrm{VO}_{2 \text { peak, }}$ respectively. ANOVA shows that $1.6 \mathrm{~m} \mathrm{~s}^{-1}$ propulsion has significantly higher values on $\% \mathrm{VO}_{2 \text { peak, }} \mathrm{V}_{\mathrm{E}}$ and RPE_respiration than do $1 \mathrm{~m} \mathrm{~s}^{-1}$ propulsion and self-selected propulsion. There was no significant difference between RPE_respiration and $\mathrm{RPE}_{-a r m}$ in any of the trials.

\section{DISCUSSION}

\section{Daily activity zone for wheelchair users}

We expected that propelling a wheelchair at the minimal functional speed $\left(1.0 \mathrm{~m} \mathrm{~s}^{-1}\right)$, functional walking speed $\left(1.3 \mathrm{~m} \mathrm{~s}^{-1}\right)$ and comfortable speed $\left(1.1 \pm 0.2 \mathrm{~m} \mathrm{~s}^{-1}\right)$ is a physical activity of low to moderate intensity. The corresponding RPE ranges from 7 to 13 on the Borg 6-20 scale; the corresponding $\% \mathrm{VO}_{2 \text { peak }}$ ranged from 37 to $80 \%$ and the $\mathrm{HR}$ from 40 to $60 \% \mathrm{VO}_{2 \text { peak }}$, with the corresponding $\mathrm{RPE}$ ranging from 7 to $10 .{ }^{12}$ Compared with able-bodied people, relatively higher $\mathrm{RPE}$ and $\% \mathrm{VO}_{2 \text { peak }}$ values reported in the daily activity intensities among wheelchair users can be attributed to the dependency on arm exercise, the extent of paralysis, reduced sympathetic control and relative inactivity, all of which can compromise physical capacity in SCI. ${ }^{13}$

We observed that participants chose a speed $\sim 1.1 \mathrm{~m} \mathrm{~s}^{-1}$ as a comfortable propelling speed on the ergometer. The corresponding intensity $\sim 53 \% \mathrm{VO}_{2 \text { peak }}$ and $\mathrm{HR}$ averaged 104 beats per min $(0.69 \%$ $\left(\mathrm{HR}_{\max }\right)$. Ratings of perceived exertion during self-selected speed propulsion averaged $8.9 \pm 1.9$ for overall rating and $9.3 \pm 2.5$ for peripheral rating. The preferred intensity of exertion selected by the participants is within expected ranges of RPE (7-12 on Borg's 6-20 scale) and relative tolerance for exercise (for example, 36-69\% of $\left.\mathrm{VO}_{2 \text { peak }}\right)$. We think the preferred intensity is safe and health promoting for most community-based wheelchair users. They are more likely to adhere to their own preferred exercise intensity than to adjust to a level based on precise physiological criteria if those criteria conflict with their intensity preference. Further studies are needed on how the preferred exercise intensity, combined with an appropriate duration and frequency, enhances health outcomes and fitnessenhancing benefits.

It is encouraging to note that, as shown in Table 4, the reported RPE in the self-selected speed $\left(\sim 1.1 \mathrm{~m} \mathrm{~s}^{-1}\right)$ bout was similar to the RPE reported in the $1 \mathrm{~m} \mathrm{~s}^{-1}$ bout. As the bout order was randomized and none of the participants had any prior exposure to RPE scales, this indicated that RPE results are fairly reproducible at similar exercise intensities.

\section{Differentiated RPE model}

Perceptual dominance has been demonstrated in able-bodied subjects performing cycle ergometer and treadmill exercises. ${ }^{14-16}$ As for wheelchair users, they rely entirely on the upper limbs for both ambulation and weight-bearing tasks. The shoulder is poorly designed for this purpose, and thus becomes exposed to excessive, repeated interarticular pressures in conjunction with a more abnormal distribution of stresses across the subacromial area. The differentiated RPE model suggests that discrete perceptual ratings are linked to 
specific underlying physiological events. ${ }^{16,17}$ We set out to examine how measured exercise intensity was reflected in differentiated RPE, considering local exertion felt specifically in the upper limbs, as well as overall exertion. It was hypothesized that wheelchair users would report a similar RPE_arm and RPE_respiration at low to moderate exercise intensities but that at the relatively higher intensities the participants might report higher RPE_arm values. In the present study, for wheelchair propulsion at low, moderate and graded exercise intensity our results showed no difference between differentiated RPE_arm and

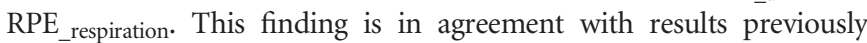
reported, which indicated no significant differences between RPE arm and RPE_respiration during moderate and vigorous exercises among trained SCI people. ${ }^{8}$ We also found that there were no significant differences between $\mathrm{RPE}_{-}$arm and $\mathrm{RPE}_{-}$respiration at the termination of the GXT. Goosey-Tolfrey and colleagues ${ }^{8}$ observed that well-trained wheelchair athletes reported significantly higher peripheral RPE compared with overall RPE at the termination of the GXT and the ramp exercise test.

Our participants are community-based wheelchair users. With a look at the years since injury, some participants with a shorter injury history did report higher RPE arm than RPE respiration. Further research is needed with a larger sample size and more homogeneous participants to test the effect of injury history and strength training of the upper limbs on differentiated RPE model.

\section{Practical applications}

Designing exercise programs manageable enough to be adhered to while sufficiently intensive to allow adequate cardiovascular conditioning are essential for individuals seeking to maintain an exercise program. Wheelchair pushing provides both cardiovascular conditioning and improves muscle endurance. ${ }^{18}$ The present study provides evidence that wheelchair users' daily mobility activities fall within a training range that would not only result in cardiovascular conditioning, but also feels most comfortable to them. Public health guidelines call for 30 min of moderate intensity exercise 'most days' (5-7 days per week) $j^{19}$ the exercise plan is based on doing 'as much as one reliably can' rather than 'as much as one possibly can'. Instructions that guide participants towards a judiciously self-selected exercise intensity may establish a sense of ownership and encourage long-term adherence among a wide range of individuals. Our results also demonstrate that RPE is a valid tool for tracking low to moderate exercise intensity.

\section{Study limitations}

Our choice of wheelchair propulsion assessment on the ergometer offered methodological benefits such as simulated graded propulsion. However, preliminary investigations prior to data collection showed that the ergometer had a higher rolling resistance than an indoor tile surface. It has been reported that propulsion velocity decreases with an increase in rolling resistance. ${ }^{20}$ That is likely to have been a factor in the relatively low self-selected speed of our participants.

The current study has shown encouraging potential for the use of RPE to monitor daily wheelchair propulsion intensity in persons with paraplegia. However, the findings of this study are limited by a small sample size. To see whether more severely impaired individuals with tetraplegia can benefit from these findings, validation within that additional group would be desirable. The effect of exercise duration and frequency is a potential avenue of enquiry to extend the recent work in this area. More studies are needed to validate the accuracy and repeatability of RPE to monitor exercise intensity, particularly when the wheelchair propulsive exercise bouts involve low to moderate intensity efforts.

\section{CONCLUSION}

This study assessed the physical capacity of community-based wheelchair users for functional wheelchair speeds that are typically required to complete activities of daily living. We found a good correlation between physical capacity and RPE during low to moderate daily activity intensities. The daily activity intensities among the participants ranges from $37-80 \% \mathrm{VO}_{2 \text { peak }}$, the RPE corresponds to these intensities ranges from 7-13. No differences between differentiated RPE respiration and RPE arm were found for wheelchair propulsion at low, moderate, high, as well as graded exercise intensities in the present study. RPE could be used as a simple tool to assess and monitor the activities in which wheelchair users engage in their daily tasks, their recreation and exercises.

\section{DATA ARCHIVING}

There was no data to deposit.

\section{CONFLICT OF INTEREST}

The authors declare no conflict of interest.

\section{ACKNOWLEDGEMENTS}

This project was funded by Alberta Paraplegia Foundation (grant award number: 19582/74) in collaboration with Rick Hansen Foundation. We thank Frank Geddes and Pamela Bentley for assistance with recruitment of participants. We thank all the participants for participating and giving feedback. We thank Jiajie Wu for assistance with data collection and Farhood Mohammadi for support with statistical analysis and Vicky Tolfrey, Loughborough University, UK, for proposing the original study design. Reprint requests to Martin Ferguson-Pell, South Academic Building, University of Alberta, Edmonton, Alberta, Canada T6G 2 G7.

1 van der Woude LH, de Groot S, Janssen TW. Manual wheelchairs: research and innovation in rehabilitation, sports, daily life and health. Med Eng Phys 2006; 28: 905-915.

2 Bauman WA, Spungen AM. Coronary heart disease in individuals with spinal cord injury: assessment of risk factors. Spinal Cord 2008; 46: 466-476.

3 Bauman WA, Spungen AM. Carbohydrate and lipid metabolism in chronic spina cord injury. J Spinal Cord Med 2001; 24: 266-277.

4 Jacobs PL, Nash MS. Exercise recommendations for individuals with spinal cord injury. Sports Med 2004; 34: 727-751.

5 Devillard X, Rimaud D, Roche F, Calmels P. Effects of training programs for spinal cord injury. Ann Readapt Med Phys 2007; 50: 480-498.

6 Eston RG, Williams JG. Reliability of ratings of perceived effort regulation of exercise intensity. Br J Sports Med 1988; 22: 153-155

7 Al-Rahamneh HQ, Eston RG. Prediction of peak oxygen consumption from the ratings of perceived exertion during a graded exercise test and ramp exercise test in ablebodied participants and paraplegic persons. Arch Phys Med Rehabil 2011; 92 277-283.

8 Lenton JP, Fowler NE, van der Woude L, Goosey-Tolfrey VL. Wheelchair propulsion: effects of experience and push strategy on efficiency and perceived exertion. App Physiol Nutr Metab 2008; 33: 870-879.

9 Goosey-Tolfrey VL, Alfano H, Fowler N. The influence of crank length and cadence on mechanical efficiency in hand cycling. Eur J Appl Physiol 2008; 102: 189-194.

10 Al-Rahamneh H, Eston R. Rating of perceived exertion during two different constantload exercise intensities during arm cranking in paraplegic and able-bodied participants. Eur J Appl Physiol 2010; 111: 1055-1062.

11 Goosey-Tolfrey VL, Lenton J, Goddard J, Oldfield V, Tolfrey K, Eston R. Regulating intensity using perceived exertion in spinal cord-injured participants. Med Sci Sports Exerc 2010; 42: 608-613.

12 Goss F, Robertson R, DaSilva S, Suminski R, Kang J, Metz K. Ratings of perceived exertion and energy expenditure during light to moderate activity. Percept Mot Skills 2003; 96: 739-747.

13 Haisma JA, van der Woude LH, Stam HJ, Bergen MP, Sluis TA, Bussmann JB. Physical capacity in wheelchair-dependent persons with a spinal cord injury: a critical review of the literature. Spinal Cord 2006; 44: 642-652. 
14 Paulson TA, Bishop NC, Eston RG, Goosey-Tolfrey VL. Differentiated perceived exertion and self-regulated wheelchair exercise. Arch Phys Med Rehabil 2013; 94: 2269-2276.

15 Faulkner J, Eston R. Overall and peripheral ratings of perceived exertion during a graded exercise test to volitional exhaustion in individuals of high and low fitness. Eur J Appl Physiol 2007; 101: 613-620.

16 Bolgar MR, Baker CE, Goss FL, Nagle E, Robertson RJ. Effect of exercise intensity on differentiated and undifferentiated ratings of perceived exertion during cycle and treadmill exercise in recreationally active and trained women. J Sports Sci Med 2010; 9: 557-563.
17 Robertson RJ, Noble BJ. Perception of physical exertion: methods, mediators, and applications. Exerc Sport Sci Rev 1997; 25: 407-452.

18 Rimaud D, Calmels P, Devillard X. Training programs in spinal co rd injury. Ann Readapt Med Phys 2005; 48: 259-269.

19 American College of Sports Medicine. ACSM's Guidelines for Exercise Testing and Prescription. Williams \& Wilkins: Philadephia, PA, USA: 2010.

20 Cowan RE, Nash MS, Collinger JL, Koontz AM, Boninger ML. Impact of surface type, wheelchair weight, and axle position on wheelchair propulsion by novice older adults. Arch Phys Med Rehabil 2009; 90: 1076-1083. 